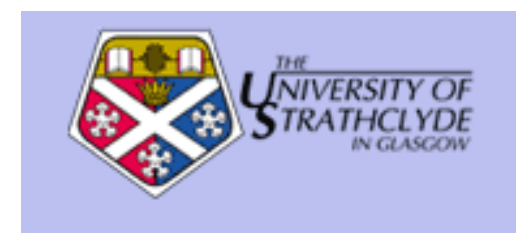

Bennett, L. and Landoni, M. (2005) E-Books in academic libraries. Electronic Library, 23 (1). pp. 9-16. ISSN 0264-0473

http://eprints.cdlr.strath.ac.uk/2744/

This is an author-produced version of a paper published in Electronic Library ISSN 0264-0473. This version has been peer-reviewed, but does not include the final publisher proof corrections, published layout, or pagination.

Strathprints is designed to allow users to access the research output of the University of Strathclyde. Copyright (c) and Moral Rights for the papers on this site are retained by the individual authors and/or other copyright owners. Users may download and/or print one copy of any article(s) in Strathprints to facilitate their private study or for non-commercial research. You may not engage in further distribution of the material or use it for any profitmaking activities or any commercial gain. You may freely distribute the url (http://eprints.collr.strath.ac.uk) of the Strathprints website.

Any correspondence concerning this service should be sent to The Strathprints Administrator: eprints@cis.strath.ac.uk 


\title{
E-books in Academic Libraries
}

\section{Linda Bennett and Monica Landoni \\ Keywords: e-book models, user profile, e-book typology}

\section{Case Study}

\begin{abstract}
Purpose

This paper provides an analysis of the current state of the art in e-books, and attempts both to set the scene and provide reasons for their low uptake.
\end{abstract}

Methodology

The different approaches to e-books of academic librarians, authors, publishers and readers are considered, using the results of a recent survey commissioned by the Joint Information Systems Committee (JISC).

Findings and Value

The findings of this study make it clear that those who know about e-books see them as potentially useful tools. However, a number of users of ICT resources are still unaware of e-books even when their academic libraries' e-book holdings is high. The lack of promotion from within the university, particularly from the academics, and to a certain extent from the librarians, is indeed a major reason for this knowledge gap.

Practical implications

Publishers, e-book providers and aggregators, academics and intermediaries (i.e., librarians and information specialists) should concentrate on raising awareness of what is available and what are the advantages related to e-books for specific categories of users. At the same time e-book suppliers should make e-books easier to find and purchase.

Crucially, both the research and commercial development communities have to address these major issues:

- Definition of common bench marks for research to progress;

- User-centred design as a paradigm;

- Better and stronger links with all stakeholders.

This paper will offer a stepping stone for all parties interested in moving forwards to achieve this common goal.

\section{Introduction}

Electronic books have been around for a quite a while now and although different stakeholders have various expectations of how they could fit into both academic and everyday life, still there is lot of confusion about them, even with regard to the basic definition of what an e-book is.

In this paper different definitions and models for e-books are examined and discussed in a critical fashion. How these theories impact on the existing examples of e-books or fail to do this is then analysed. Different types of e-books are described, with reference to their advantages and disadvantages, placing the emphasis on how they fit in with users' 
needs and expectations. This is crucial, since users' expectations are at this stage playing a crucial role in determining the fortune of e-books. A brief analysis of users' profiles in relation to different models of e-books and their features is therefore provided. A comparison is suggested between different types of paper books that have naturally evolved to satisfy specific needs of individuals and communities and the current development of e-books from a by-product of the Hypertext community to web-delivered packaged information. At this point, a simple four-dimensional definition of e-books is introduced to facilitate discussion, these four main dimensions being: content, format, purpose and use. The role of e-books in a digital library is then discussed and a number of possible scenarios described. Education and e-learning are explored as offering a promising environment within which e-books could have a positive impact. The approaches to e-books of academic librarians, authors, publishers and readers are considered, using the results of a recent survey commissioned by the Joint Information Systems Committee (JISC). The paper then concludes with a discussion on how e-books could become more widely used and have a positive impact on different type of readers.

\section{Definitions and Models}

A book or document can be understood in general terms as a medium for communicating information, where information is taken to include facts, teaching material, discursive writing and fiction. An electronic book (or e-book) is, or should be, its digital equivalent, a medium where information is organised and structured so that it can be presented to the reader in order to facilitate consultation (Landoni, 2003). Consultation is an activity that would normally include at least the following basic actions: browsing, searching, extracting, comparing and assessing relevance and quality of information presented. The design of e-books needs to take into account advantages and disadvantages in terms of legibility, portability and autonomy of the medium by which they are hosted (Wilson et al, 2003). There is of course a growing range of so-called e-book readers, that is, devices created specifically for storing and reading e-books, each of them exploiting one aspect of the paper book metaphor that is portability. Screen resolution is still not comparable with paper resolution, and this has both inspired research in the area of technical quality and created the perception that there is a need for extra value to be added to e-books in 
order to justify the discomfort of "reading" them on a relatively poor resolution screen. The main models that have inspired the design of e-books have taken as their startingpoint paper books and their physical appearance, logical structure and usage. Working from this, e-book modifications considered desirable have included lower numbers of words per page, title headings on each page, clearer page layouts, typographical clues and tools for searching and browsing (indexes and tables of contents, bookmarks and annotations, etc.) What has not yet been taken into consideration is the diversity of presentation styles that are appropriate to different types of books, according to their content, use and intended audience. There are promising indications that personalisation and user customisation will be the core of the next generation of e-books and e-readers (Wilson et al, 2002).

To take the obvious parallel in publishing, it would be useful to look at how paper books have evolved in format (both in appearance and functionality) to match their individual category and purpose. For example, children's books are different from adults' scientific publications, which are different again from novels; encyclopaedias differ from monographs, textbooks from art books and so on. There are subtle differences within each genre: sometimes the same title can be produced in different editions with different formats in order to target a specific reader group. This is why, just to mention a very popular example, there are child and adult editions of the Harry Potter saga which contain the same content in a different package (the font, size, title page and overall presentation style have been changed according to readership). This ingenious system of matching the reader to his or her likely favoured version of a title can be taken much further by e-books. Instead of targeting just a few different user-group categories, ebooks can be designed to fit in with each individual's needs and profile. Current e-book research reveals positive signs that this refined functionality can provide a very powerful tool to support individuals in their reading needs. This is particularly exciting when one considers that the potential that it offers to education at all levels, from preschool children right through to those studying in further or higher education. If it is a requirement that e-books should provide extra value, it follows that this is a worthwhile direction for development work to go in order to make a real impact both within and beyond the education community. 
Some inspiration has to be taken from the different types of paper books that have naturally evolved to satisfy specific needs of individuals and communities . Creativity and user-centred design, not market issues, should be at the core of e-book design ; and research into how this can best be delivered will be worthwhile indeed.

\section{E-book: Content, Format, Purpose and Use}

In order to help the sparsely-resourced and diverse community of e-books designers, publishers and providers, more needs to be done to make sure that there is a common understanding of what e-books are and can do. Whilst we await the magic moment when all different actors in the e-book market can share a common definition and vision, the research community itself is in need of common benchmarks which would allow us to evaluate new paradigms of e-books. A mechanism for sharing and comparing results is also needed, so that it may be possible to build on each other's experience instead of reinventing the wheel.

One way of looking at e-books is by adopting a user- centred approach, that is, by defining them as a four dimensional vector. The four vectors are: Content, Format, Purpose and Use.

By referring again to the parallel already drawn with paper books, it will become clear that content is crucial in dictating for whom and how e-books should be designed; and that the format should be dictated by purpose, not vice versa. E-book design then becomes a two- step process, in which an analysis of user requirements yields a user profile that may then be utilised to develop the optimum format.

\section{E-books in Education}

When considering the potential for using e-books in education, educators, students, librarians and e-books provider should try to arrive at a common understanding of the potential of e-books, rather than focusing on what is currently available. NetLibrary and ebrary, as the biggest e-book aggregators and providers for education, have been dictating the rules of engagement for too long, and shown too little sign of wishing to listen to user concerns. Even in the current environment, which is made up of a 
relatively limited amount of available titles and a poor but slowly improving mechanism to access them, there are signs that e-books can become a promising resource in education.

Realising this, the Joint Information Systems Committee (JISC) commissioned a study from Gold Leaf in 2003 which examined the barriers to uptake of e-books in the HE and FE communities, and what types of promotion they might require in order to gain better recognition and usage in education. The report, which is available from the JISC website ${ }^{1}$, was delivered in the autumn of 2003.

The report, which involved consultation with all stakeholders is lengthy and difficult to summarise. However, the key points that it makes include:

- Within the context of academic publishing, there is not an adequate definition for the term "e-book"; this constitutes a source of confusion and therefore a barrier to uptake.

- The wide diversity of software and hardware products associated with e-books are a cause of confusion and therefore constitute a further barrier to uptake.

- E-books could help to solve some of the challenges currently facing further and higher education, including a burgeoning student population, a changing student profile, the advent of MLEs and VLEs, and students' lack of funds for purchasing texts.

- Currently there are significant differences between the print book and e-book physical and information supply chains. The e-book information supply chain is imperfect. Awareness of the main user groups, especially of academics, lecturers and students, but also, in some cases and for some products, librarians, is low. This constitutes a major barrier to uptake.

- Many publishers are reluctant to make their publications available in e-book format and / or to promote them too strenuously, because they are afraid of the effect on their revenues. This is especially true of the major textbook publishers,

\footnotetext{
${ }^{1}$ http://www.jisc.ac.uk/coll ebookstudy2.html
} 
who have instead invested heavily in producing supplementary / complementary electronic materials to support print books.

- Both publishers and aggregators have developed a wide range of pricing models for e-books, some of which are difficult to understand.

- Booksellers have been slow to experiment with selling e-books. Therefore the important role of information providers that they fulfil in the traditional supply chain is missing from the e-book supply chain.

- Because of all these reasons, the survey found that actual expenditure on e-books by both HEI and FE institutions was low. In university libraries, the average spend figure per institution was $£ 10,546$, against an average spend of $£ 316,394$ on print books. The highest and lowest spending old universities spent $10 \%$ and $0.03 \%$ respectively of their print book expenditure on e-books. The highest and lowest spending new universities spent $10 \%$ and $0.07 \%$ respectively.

- The survey only found a small sample of FE colleges (7 out of 37 questioned) that subscribed to e-books. Of these, the average spend on e-books was $5 \%$ of the spend on print books. The average spend figure was £2,488 per institution, against an average spend of $£ 50,833$ on print books.

- 24 academics were questioned, from six universities. Despite the fact that these academics had been "hand-picked" by librarians who identified them as having an active interest in e-books, 6 of them (25\%) did not know that the university had an e-books collection and $9(37 \%)$ were not using ebooks at all. Of those who were using them, the purposes to which they put e-books were fairly evenly spread: $33 \%$ were using them for lecture preparation, $38 \%$ to prepare course material, $38 \%$ to carry out research, $8 \%$ to consult tables and formulae, $42 \%$ for general reference, and $42 \%$ for private reading / pleasure. The academics were likely to obtain e-books from a variety of sources, of which the university library $(75 \%)$ was predominant. $13 \%$ were also likely to obtain them from other libraries, $21 \%$ direct from the publisher, $21 \%$ from booksellers, and $58 \%$ were likely to obtain them free from the Internet $20 \mathrm{FE}$ lecturers were questioned, from $16 \mathrm{FE}$ colleges. The respondents answered a request for help put out through JISC, and therefore 
comprised a more random sample than the academics. Despite this, it became apparent that most of the FE respondents were enthusiastic users of e-learning applications, and the use of e-books by the FE lecturer group (at 55\%) was only $8 \%$ lower than for the academics. Only $25 \%$ of the FE lecturers were aware that their college had an e-books collection. It was without the scope of the study to check on how many of the colleges concerned actually had e-books collections, but at least one of the lecturers was unaware that his college held a (considerable) e-book resource. $25 \%$ of the FE lecturers used e-books for lecture preparation; $45 \%$ to prepare course materials / handouts; $30 \%$ to carry out research; $5 \%$ to consult tables or formulae; $45 \%$ for reference information; and $10 \%$ for private reading or pleasure. $30 \%$ of them were likely to obtain e-books from the college library; $20 \%$ were likely to obtain them from other libraries; $35 \%$ were likely to obtain them direct from publishers; $5 \%$ from booksellers, and $60 \%$ were likely to obtain them free from the Internet, making this by far their most likely single source.

- 28 students were questioned, both by questionnaire and by taking part in focus groups. They were a mixture of undergraduates and postgraduates from 3 different universities. Each of these universities had an e-books collection, and $54 \%$ of the students were aware of this. $88 \%$ of the students had attended a library training session, and $58 \%$ of these remembered that it had included information about e-books (according to the librarians, all of the sessions concerned had contained this information). $88 \%$ of the students used the web for studying and learning, and $39 \%$ of these used e-books. $3 \%$ of the students were likely to use e-books to prepare for lectures and seminars; none were likely to use them to help prepare for examinations; $32 \%$ were likely to use them to aid in the preparation of essays and coursework; $7 \%$ were likely to use them to consult tables and formulae; $18 \%$ were likely to use them for general reference information; none was likely to use them for private reading / pleasure. A significant finding was that the students were uncertain about where to obtain ebooks. As part of their introductory brief, they were told that the library had an e-books collection, and $75 \%$ then said that they would be likely to try to obtain ebooks from the library. $25 \%$ said that they would be likely to obtain e-books from 
other libraries; 11\%, direct from the publishers; 11\%, from booksellers; and 18\% said that they would be likely to obtain e-books free from the Internet. It was not possible to gain a significant number of responses from FE students.

- The study found that some academics and lecturers use e-books in very innovative ways, and their ideas could (and should) be disseminated more widely.

- Students, on the other hand, and many academics, are confused about e-books and very imperfectly aware of them. However, most are willing to try them once their awareness has been raised. Within this context, it is particularly important that e-books should feature on the main vehicle of information used by students and teaching academics: the reading list. However, at present this is rarely the case.

- Among the issues to be resolved by e-books providers, the greatest single barrier to uptake with regard to software and hardware is the lack of a common platform for e-books.

- Assessing potential demand for e-books is difficult, because of the imperfect supply chain already identified, and because usage statistics provided by publishers and aggregators are often difficult to understand and invariably inadequate for determining the quality and extent of usage. Some modest lending successes and a few spectacular ones were identified during the survey by referring to such usage statistics as were available. However, the following statistic is more significant in establishing potential demand for e-books in higher and further education: $71 \%$ of the academics, $80 \%$ of the FE lecturers and $72 \%$ of the students that took part in the study said that they would buy the e-book in preference to the print book if it were significantly cheaper (regardless of whether or not there is "added value" in terms of functionality).

- The study also examined the cataloguing and metadata issues relating to e-books, but these are too complex to summarise in this article. Those who wish to know more should turn to Chapter Eight of the report, which also contains a series of case studies demonstrating best practice. A separate manual for librarians is also available as a companion to the main report.

The findings of this study make it clear that those who know about e-books see them as potentially useful tools. However, the findings also show that the number of users of ICT 
resources unaware of e-books, and indeed their academic libraries' e-book holdings, was high. The lack of promotion from within the university, particularly from the academics, and to a certain extent from the librarians, was a major reason for this knowledge gap. For everyone involved the social inclusion offered by e-books is an attractive quality. However, on a realistic note, not everyone has computer access, and while this is a much bigger issue than just for e-books, it is important within the e-book context that libraries, and universities generally, continue to improve computer access on-campus. Librarians must also be careful to provide simple, clear and comprehensive e-book training for all library users. Staffordshire University Library, one of the best practice cases cited, offers training by subject for each undergraduate and postgraduate year by subject, as well as annual training by subject for the academics.

\section{Conclusions and Discussion}

Although the majority of users interviewed expressed a willingness to use e-books in the future, it was clear that many feel that currently the usability of e-books is too poor to offer a genuine alternative to printed resources for serious academic study. The quality of the content is also huge issue, and the ability of users to assess the quality influences use, particularly within the academic community. To have e-books (if produced as original documents, as opposed to electronic versions of previously-produced paper documents) reviewed by reputable academics, academic and library journals, publishers and booksellers, just like printed books, will ensure increased user confidence in the quality of the material.

Money influences the decision to purchase e-books for libraries, since they need to make not just "one off" purchases but continue to fund annual access fees. Given the limited nature of library budgets, that leaves them with difficult choices as to how best to serve their user's needs. For users, the cost of hardware, Internet access and the fact that ebooks currently cost a similar amount to printed books, influences their choices. While it is not possible for those involved in e-book production to change the technological infrastructure, sales models and pricing structures certainly come within their remit. If e-books are to be widely used, the funding and revenue issues of the two main groups of stakeholders, i.e., librarians and academics on the one hand, and publishers and aggregators on the other, will have to be intelligently resolved. 
One of the main ways that this can be achieved is by increasing the "added value" qualities of e-books. Chief among these is the ability to run keyword searches over the ebook, or e-book collection; this is obviously a major advantage, and is one of the reasons why e-journals have become such an indispensable tool for many researcher using online facilities. With e-books, users' current reliance on printing negates the benefits that ebooks offer and adds additional costs. There are copyright and technological issues that have yet to be resolved in this context. While the problems of reading from a screen will not disappear completely until the technology improves, it is important that the use of ebooks on the computer screen only is promoted. This can only be achieved if value is added to them at the design stage.

Publishers and vendors are clearly going to play an important role in the adoption of ebooks within HE libraries. Academic libraries have tight budgets so it is important that the resources they buy are justifiable and well-used by students and academics. However, librarians should understand that the models must accommodate the commercial viability of the publisher as well. It would go a long way to resolving some of these issues if, as well as offering high quality material in a mutually acceptable sales model, publishers and other e-book vendors would work on developing a method for preservation and continued future access. The British Library should also play its part by developing a proper, comprehensive e-resources archive. Until these developments take place, academics, librarians, students and researchers are going to be difficult to convince that e-books offer a benefit beyond providing additional copies of existing printed texts.

For libraries, the problems of making sure these new e-resources are available for use is more than just a marketing issue. E-books require cataloguing, integration with other library resources and easy location by users. From the study it was clear that borrowers, particularly those who are currently not e-book users, will look to the library as their main resource for e-books, so it is important that the e-books are easily retrievable from the library catalogue. There is much work to be done on this, and JISC is about to commission a further study on e-books metadata and interoperability.

At the moment, there is no suggestion that the emergent resource of e-books will replace existing information resources, rather than just supplement them. New 
technological developments do have to be made in order to give e-books a more centrestage role. However, the really crucial issue is that, if e-books are to reach their full potential, they will have to offer more than simply an electronic version of the printed book. Librarians need to promote e-books and educate users, as well as staff, about their benefits and use. Users require a shift in attitude away from the current perception that everything must be on the printed page, towards the varied possibilities offered by ebooks. Publishers, other vendors and librarians need to work together on more mutually congenial business models.

\section{References}

Landoni M. (2003): Electronic books. Feather \& Sturges (eds): Routledge International Encyclopaedia of Information and Library Science (2/e), London: Routledge. 168-171.

Wilson R., Landoni M. and Gibb F (2003) The WEB Book experiments in electronic textbook design. Journal of Documentation, 59 (4), 2003.

Wilson R., Landoni M. and Gibb F (2002): A user-centred approach to ebook design. The Electronic Library, 20 (4) 2002. 